\title{
The fatigue, sleep and physical activity in postoperative patients with pituitary adenoma: what we can do
}

\author{
Xin Zhao ${ }^{1}$, Ting Wang ${ }^{1}$, Guixiao Sheng ${ }^{1}$, Yanyao Tang ${ }^{1}$, Meifen Shen ${ }^{2}$, Jianping Yang ${ }^{3}$ \\ ${ }^{1}$ School of Nursing, Medical Department, Soochow University, Suzhou 215006, China; ${ }^{2}$ Department of Neurosurgery, ${ }^{3}$ Department of \\ Anesthesiology, the First Affiliated Hospital of Soochow University, Suzhou 215006, China \\ Contributions: (I) Conception and design: X Zhao, M Shen; (II) Administrative support: J Yang; (III) Provision of study materials or patients: M Shen; \\ (IV) Collection and assembly of data: X Zhao, T Wang, Y Tang; (V) Data analysis and interpretation: X Zhao, M Shen, J Yang; (VI) Manuscript \\ writing: All authors; (VII) Final approval of manuscript: All authors. \\ Correspondence to: Meifen Shen, Jianping Yang. No. 1 Shizi Road, Suzhou 215006, China. Email: smf8165@126.com; chen04680@126.com.
}

\begin{abstract}
Background: To evaluate the current status of fatigue, sleep and physical activity in postoperative patients with pituitary adenoma (PA).

Methods: Postoperative patients undergoing PA resection from November 2017 to November 2018 were identified. A multi-centered survey was conducted with questionnaires on the characteristics of included PA patients, multidimensional fatigue inventory (MFI-20), the Pittsburgh sleep quality index (PSQI) questionnaire, and the international physical activity (IPA) questionnaire. The related scores and potentially influencing factors were analyzed accordingly.

Results: A total of 184 patients were included. The time course after operation, PSQI were correlated with the scores of general fatigue, physical fatigue, reduced activity and reduced motivation (all $\mathrm{P}<0.05$ ); PSQI and IPA, the time course after operation and gender were the independent factors associated with the level of general fatigue (all $\mathrm{P}<0.05$ ); PSQI, IPA and the time course after operation, adenoma size and gender were the independent factors influencing the level of physical fatigue (all $\mathrm{P}<0.05$ ); the time course after operation, IPA, PSQI and gender were the independent factor influencing the level of reduced activity (all $\mathrm{P}<0.05$ ); the time course after operation, IPA, PSQI and adenoma size were the independent factor influencing the level of reduced motivation (all $\mathrm{P}<0.05$ ); the time course after operation was the independent factor influencing the level of mental motivation $(\mathrm{P}=0.030)$.
\end{abstract}

Conclusions: Fatigue in PA patients after surgery is inversely associated with the time course after surgery and physical activity, future studies on the related interventions are warranted.

Keywords: Fatigue; sleep; physical activity; pituitary adenoma (PA); surgery

Submitted Oct 04, 2019. Accepted for publication Jan 18, 2020.

doi: $10.21037 /$ tcr.2020.02.47

View this article at: http://dx.doi.org/10.21037/tcr.2020.02.47

\section{Introduction}

Pituitary adenoma (PA) is the most common saddle-area tumor, which mainly occurs in young adults with prevalence of ranging from one in 865 adults to one in 2,688 adults (1). The growth of PA lead to endocrine dysfunction and central nervous compression, thereby causing related symptoms (2). Although PA is generally benign and it can be surgically removed, there are still some abnormal symptoms after surgery, which leads to the quality of life of surgical patients being damaged $(3,4)$. Among postoperative symptoms, fatigue is a relatively widespread complaint (5). Previous studies (6) have reported that PA patients have significantly increased fatigue and decreased vitality compared with health populations. However, it's been reported that there were no significant differences in fatigue scores between the four types of PA patients, namely, Cushing's disease, acromegaly, prolactinoma, and non-functional adenoma 
$(7,8)$. Therefore, the fatigue and physical activity in patients with PA need further clarification.

Regarding the cause of fatigue, some scholars $(9,10)$ believe that it may be related to postoperative pituitary dysfunction. However, previous study $(11,12)$ has reported that even for the PA patients with hormone replacement therapy, the patient's fatigue still exists, which may be explained that the endocrine replacement therapy cannot completely simulate the physiological activity of normal pituitary hormone secretion (13). Additionally, in patients with PA who are not hormone-deficient, there are some reports of increased drowsiness and fatigue (14). Therefore, some researchers (15-17) believe that fatigue is associated with abnormal sleep rhythm, especially when the tumor is large enough to injury the upper nucleus, the circadian rhythm can be seriously damaged. Physical activity is often significantly associated with fatigue, and it is even considered as one of the measures to alleviate fatigue $(18,19)$, but in the relevant reports of patients with PA, little attention is paid to physical activity. Based on literature review, we have presumed that the sleep and physical activity in PA patients are closely related with the fatigue level. Currently, the related studies are very rare, it's necessary to identify the current status of sleep, fatigue and physical activity in postoperative patients with PA. Therefore, we have attempted to conduct a survey to understand the fatigue, sleep, and physical activity of PA patients after surgery, to provide insights into the clinical management of PA patients.

\section{Methods}

\section{Ethical considerations}

This study was approved by the Medical Research Ethics Committee of First Affiliated Hospital of Soochow University (No.20170167).

\section{Participants}

From November 2017 to November 2018, postoperative patients undergone PA resection in the neurosurgery departments of two tertiary hospitals were recruited. The inclusion criteria were as follows: adult patients with age $\geq 18$ years old; they underwent PA resection in the two designated hospitals; the clinical data were complete. Patients under the age of 18 , patients with other kinds of cancer were excluded from this present study.

\section{Survey process}

The survey was conducted using uniform guideline with several questionnaires that included a questionnaire on the characteristics of included PA patients, Multidimensional Fatigue inventory (MFI-20), the Pittsburgh Sleep Quality Index (PSQI) questionnaire, and the International Physical Activity (IPA) questionnaire.

\section{Questionnaire on the patients' characteristics}

There are 14 items including gender, age, education background, PA type etc., which are used to understand the general demographic characteristics and disease-related information of included PA patient.

\section{MFI-20}

The MFI-20 was designed by Smets in 1993, it consists of 20 items with 5 dimensions, namely general fatigue, physical fatigue, reduced activity, reduced motivation and mental fatigue.

PSQI This tool was developed for the evaluation of sleep quality by Dr. Buysse, a psychiatrist at the University of Pittsburgh. The score is ranged from 0 to 21 . The higher the score, the worse the sleep quality.

\section{IPA}

IPA was developed in 2001 by the International Consensus Group on Physical Activity Measurement to assess the level of physical activity in adults, the questionnaire calculates the total weekly activity level according to the time of individual reports of different intensity activities per week, the physical activity can be divided into high, medium and low levels.

\section{Statistical analysis}

Statistical analysis was performed using SPSS 21.0 (SPSS Inc., Chicago, USA). Kolmogorov-Smirnov was used to test whether the continuous data conformed to the normal distribution. The scores of each fatigue subscale were analyzed by independent sample $t$ test, one-way ANOVA and post hoc analysis. Spearman correlation analysis were conducted to evaluate the potential relationship, and multiple stepwise regression analysis were performed to identify the influencing factors of fatigue. All of the $p$ values were 2 tailed, and $\mathrm{P}<0.05$ was considered as being statistically significant. 
Table 1 The characteristic of included PA patients (n=184)

\begin{tabular}{|c|c|c|c|}
\hline Characteristic & Items & $\mathrm{n}$ & $\%$ \\
\hline \multirow[t]{2}{*}{ Gender } & Male & 81 & 44 \\
\hline & Female & 103 & 56 \\
\hline \multirow[t]{2}{*}{ Marital status } & Married & 169 & 91.8 \\
\hline & Single & 15 & 8.2 \\
\hline \multirow[t]{4}{*}{ Living together with } & Spouse & 143 & 77.7 \\
\hline & Children & 19 & 10.3 \\
\hline & Parents & 7 & 3.8 \\
\hline & Alone & 15 & 8.2 \\
\hline \multirow{4}{*}{$\begin{array}{l}\text { Educational } \\
\text { background }\end{array}$} & Elementary school & 16 & 8.7 \\
\hline & Junior high school & 48 & 26.1 \\
\hline & High school & 62 & 33.7 \\
\hline & College & 58 & 31.5 \\
\hline \multirow{6}{*}{$\begin{array}{l}\text { The type of pituitary } \\
\text { tumor }\end{array}$} & Prolactinoma & 59 & 32.1 \\
\hline & Growth hormone tumor & 26 & 14.1 \\
\hline & ACTH tumor & 12 & 6.5 \\
\hline & Thyrotropin tumor & 4 & 2.2 \\
\hline & Non-functional tumor & 80 & 43.5 \\
\hline & Others & 3 & 1.6 \\
\hline \multirow[t]{3}{*}{ Adenoma size } & Microadenoma ( $\leq 10 \mathrm{~mm})$ & 50 & 27.2 \\
\hline & Large adenoma (10-40 mm) & 122 & 66.3 \\
\hline & Giant adenoma ( $\geq 40 \mathrm{~mm})$ & 12 & 6.5 \\
\hline \multirow{12}{*}{$\begin{array}{l}\text { The time course after } \\
\text { operation(months) }\end{array}$} & 1 & 15 & 8.2 \\
\hline & 2 & 17 & 9.2 \\
\hline & 3 & 11 & 6 \\
\hline & 4 & 11 & 6 \\
\hline & 5 & 16 & 8.7 \\
\hline & 6 & 15 & 8.2 \\
\hline & 7 & 17 & 9.2 \\
\hline & 8 & 16 & 8.7 \\
\hline & 9 & 9 & 4.9 \\
\hline & 10 & 15 & 8.2 \\
\hline & 11 & 14 & 7.6 \\
\hline & 12 & 28 & 15.2 \\
\hline
\end{tabular}

Table 1 (continued)
Table 1 (continued)

\begin{tabular}{llrc}
\hline Characteristic & Items & $\mathrm{n}$ & $\%$ \\
\hline Combined disease & Hypertension & 49 & 26.6 \\
& Heart disease & 5 & 2.7 \\
& Diabetes & 18 & 9.8 \\
& Others & 4 & 2.2 \\
& None & 116 & 63 \\
First surgery & Yes & 156 & 84.8 \\
& No & 28 & 15.2 \\
Hormone therapy & Yes & 21 & 11.4 \\
& No & 163 & 88.6 \\
Category of hormone & Bromocriptine & 8 & 38.1 \\
therapy drugs $(\mathrm{n}=21)$ & Glucocorticoid & 8 & 38.1 \\
& Thyroxine & 5 & 23.8 \\
& Testosterone & 1 & 4.8 \\
\hline
\end{tabular}

\section{Results}

\section{The characteristics of $P A$ patients}

A total of 184 patients were included in this present study. The age of included patients ranged from 19-79 years old with an average age of $48.56 \pm 12.18$. The characteristics of PA patients are shown in Table 1.

\section{The correlation analysis of postoperative time course, PSQI score and various fatigue scores}

Table 2 presents the correlation analysis of postoperative time course, PSQI score and various fatigue scores. Results indicated that the time course after operation, PSQI were correlated with the scores of general fatigue, physical fatigue, reduced activity and reduced motivation (all $\mathrm{P}<0.05)$.

\section{The factors for general fatigue}

Table 3 presents the multiple stepwise regression analysis on the factors for general fatigue. The results indicated that PSQI and the rating level of IPA, the time course after operation and gender were the independent factors influencing the level of general fatigue $($ all $\mathrm{P}<0.05)$. 
Table 2 The correlation analysis of postoperative time course, PSQI score and various fatigue scores ( $\mathrm{n}=184$ )

\begin{tabular}{|c|c|c|c|c|c|}
\hline Items & General fatigue & Physical fatigue & Reduced activity & Reduced motivation & Mental fatigue \\
\hline$r$ & -0.35 & -0.36 & -0.44 & -0.35 & -0.18 \\
\hline$P$ & $<0.001$ & $<0.001$ & $<0.001$ & $<0.001$ & 0.02 \\
\hline \multicolumn{6}{|l|}{ PSQI } \\
\hline$P$ & $<0.001$ & $<0.001$ & $<0.001$ & $<0.001$ & 0.84 \\
\hline
\end{tabular}

Table 3 Multiple stepwise regression analysis on the factors for general fatigue

\begin{tabular}{|c|c|c|c|c|c|c|c|}
\hline Items & B & $E$ & $\beta$ & $t$ & $\mathrm{P}$ & \multicolumn{2}{|c|}{$95 \% \mathrm{Cl}$} \\
\hline Constant & 9.90 & 1.42 & & 7.00 & $<0.001$ & 7.11 & 12.69 \\
\hline PSQI & 0.48 & 0.07 & 0.44 & 6.94 & $<0.001$ & 0.34 & 0.62 \\
\hline The rating level of International Physical Activity & -1.43 & 0.44 & -0.20 & -3.27 & 0.001 & -2.29 & -0.57 \\
\hline Gender & 1.19 & 0.47 & 0.15 & 2.55 & 0.010 & 0.27 & 2.11 \\
\hline
\end{tabular}

Adjusted $\mathrm{R}^{2}=0.37$

Table 4 Multiple stepwise regression analysis on the factors for physical fatigue

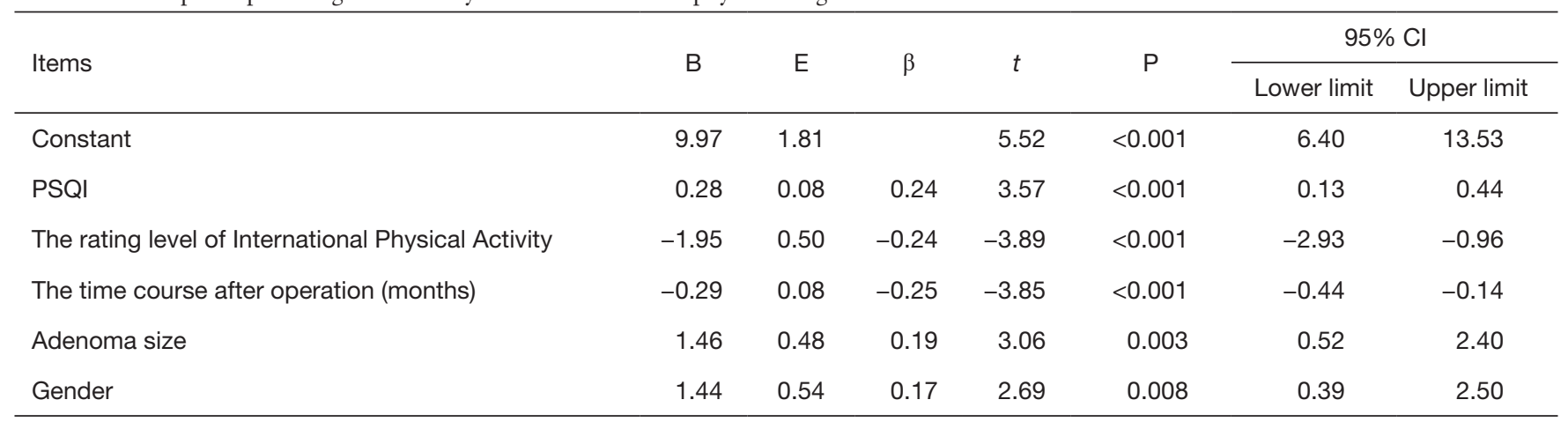

Adjusted $\mathrm{R}^{2}=0.31$

\section{The factors for physical fatigue}

Table 4 shows the multiple stepwise regression analysis on the factors for physical fatigue. The results indicated that PSQI, the rating level of IPA and the time course after operation, adenoma size and gender were the independent factors influencing the level of physical fatigue (all $\mathrm{P}<0.05)$.

\section{The factors for reduced activity}

Table 5 presents the multiple stepwise regression analysis on the factors for reduced activity. Results indicated that the time course after operation, the rating level of IPA, PSQI and gender were the independent factor influencing the level of reduced activity $(\mathrm{P}<0.05)$.

\section{The factors for reduced motivation}

Table 6 presents the multiple stepwise regression analysis on the factors for reduced motivation. The results indicated that the time course after operation, the rating level of 
Table 5 Multiple stepwise regression analysis on the factors for reduced activity

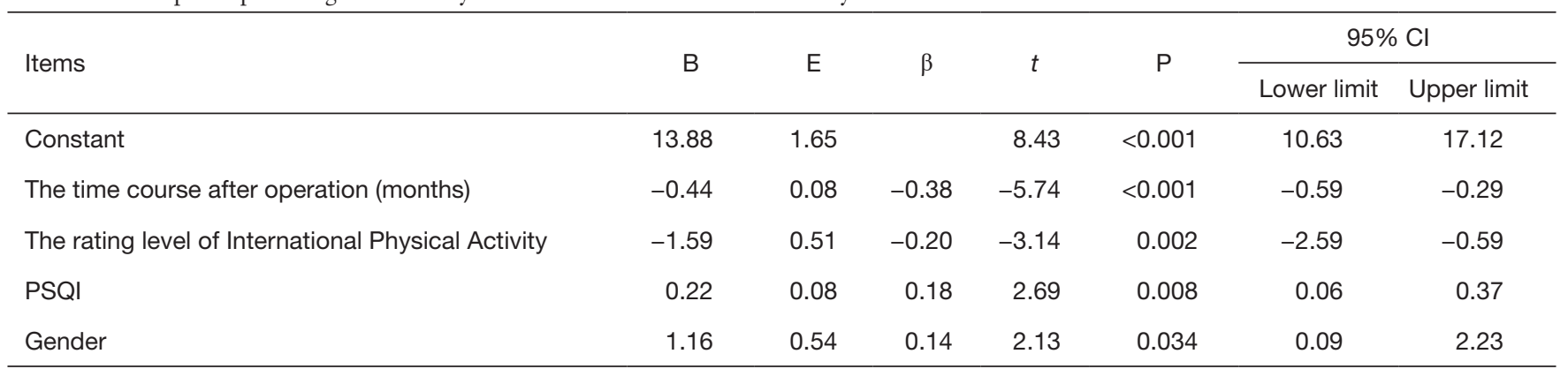

Adjusted $R^{2}=0.30$.

Table 6 Multiple stepwise regression analysis on the factors for reduced motivation

\begin{tabular}{|c|c|c|c|c|c|c|c|}
\hline Items & B & $\mathrm{E}$ & $\beta$ & $t$ & $\mathrm{P}$ & \multicolumn{2}{|c|}{$95 \% \mathrm{Cl}$} \\
\hline Constant & 10.07 & 1.03 & & 9.82 & $<0.001$ & 8.04 & 12.09 \\
\hline The time course after operation (months) & -0.21 & 0.05 & -0.28 & -4.02 & $<0.001$ & -0.31 & -0.10 \\
\hline The rating level of International Physical Activity & -1.30 & 0.33 & -0.26 & -3.89 & $<0.001$ & -1.96 & -0.64 \\
\hline Adenoma size & 0.72 & 0.33 & 0.15 & 2.22 & 0.030 & 0.08 & 1.36 \\
\hline
\end{tabular}

Adjusted $\mathrm{R}^{2}=0.22$

Table 7 Multiple stepwise regression analysis on the factors for mental fatigue

\begin{tabular}{|c|c|c|c|c|c|c|c|}
\hline Items & $\mathrm{B}$ & $\mathrm{E}$ & $\beta$ & $t$ & $\mathrm{P}$ & \multicolumn{2}{|c|}{$95 \% \mathrm{Cl}$} \\
\hline Constant & 10.42 & 0.24 & & 42.76 & $<0.001$ & 9.94 & 10.90 \\
\hline The time course after operation (months) & -0.07 & 0.03 & -0.16 & -2.17 & 0.030 & -0.13 & -0.10 \\
\hline
\end{tabular}

Adjusted $R^{2}=0.02$.

IPA, PSQI and adenoma size were the independent factor influencing the level of reduced motivation (all $\mathrm{P}<0.05$ ).

The factors for mental fatigue

Table 7 shows the multiple stepwise regression analysis on the factors for mental fatigue. The results indicated that the time course after operation was the independent factor influencing the level of mental motivation $(\mathrm{P}=0.030)$.

\section{Discussion}

$\mathrm{PA}$ is the most common tumor in the sellar region and the third common tumor related disease among craniocerebral surgery (20). It's been reported that the PA accounts for about $10 \%$ to $25 \%$ of intracranial tumors (21). Most PA are benign tumors, only $0.1 \%$ to $0.2 \% \mathrm{PA}$ are invasive, and the degree of malignancy is generally related to prognosis of PA patients (22). The clinical manifestations of PA are mainly the abnormalities of endocrine hormones and the symptoms of tumor compression on surrounding tissue structures. The goal for PA treatment is to eliminate tumor compression, protect nerve function, restore hormone and metabolic order (23). Numerous studies $(16,24,25)$ have reported that PA patients have symptoms such as fatigue, infertility, daytime sleepiness, sleep disturbance, depression and anxiety, etc., which often persist even after $\mathrm{PA}$ resection. The complications and high recurrence rate 
of PA have caused major blows to patients, and patients often cannot adapt properly (26). Therefore, understanding the current status and risk factors for the sleep, fatigue and physical activity in postoperative patients with PA is very essential. The results of this present survey have indicated that the shorter the postoperative time course, the greater the degree of general fatigue, physical fatigue, reduced activity, reduced motivation, and mental fatigue. Additionally, all types of fatigue but not the mental fatigue, are also significantly related to gender, sleep status and the level of physical activity. The type of PA and the hormonal status of the postoperative patient, whether or not to receive hormonal therapy, whether or not to have a basal disease, whether or not recurrence, and the degree of fatigue were not related.

The sleep condition of PA patient surgery was generally acceptable in this present study. $81 \%$ PA patients have subjectively thought that their quality of sleep is good or better, but there are nearly $40 \%$ PA patients have complained that there is dysfunction in the daytime sleep. Patients in the post-rehabilitation period are mainly homebased with insufficient physical strength and energy. The abnormal state of postoperative sleep is also present in other disease related populations $(27,28)$. It's been reported that there was abnormal sleep in patients with non-functional adenomas from 1 to 18 years after operation (29). It may be explained that the patient's circadian rhythm is disturbed by the tumor or surgery (30). However, this report mainly focused on non-functional large glands, in patients with other types of tumors, the causes of sleep abnormality have yet to be further confirmed.

In our study, more than $70 \% \mathrm{PA}$ patients have a low overall level of physical activity, which may be related to the modern sedentary lifestyle, the PA patient is mainly at home during the postoperative rehabilitation period, thus they rarely engaged in medium and heavy level of physical activity. In addition, in order to avoid cerebrospinal fluid leakage after transsphenoidal approach, PA patients after surgery are generally instructed to avoid over-intensity activities. The related experts (31) have reached consensus on behavioral activities after transsphenoidal approach for PA, namely mental workers can start work 2 weeks after surgery, while manual workers need to wait 4 weeks, and the competitive sports should be proceeded more than 6 weeks after surgery.

The results have shown that there is a negative correlation between postoperative fatigue and postoperative time course for patients with $\mathrm{PA}$, indicating that as the postoperative time progressed, the patient gradually recover and the fatigue in each dimension gradually ease. The general fatigue, physical fatigue, reduced activity and reduced motivation were positively correlated with sleep dysfunction, which is similar to the results of previously published studies $(32,33)$. Sleep is important for the recovery of physical fitness, people with insufficient sleep or abnormal sleep are often accompanied by varying degrees of fatigue $(6,34,35)$. In addition, the patient's fatigue is also significantly negatively associated with the level of physical activity, and patients with less physical activity are with higher level of fatigue (36). Proper physical activity helps maintain muscle strength, patients with less postoperative activity will have reduced muscle strength, decreased muscle strength, which is one of the mechanisms leading to fatigue after surgery $(37,38)$. In this present study, the level of physical activity of PA patients after surgery is relatively low. Therefore, it is potentially possible to increase the postoperative physical activity to reduce the postoperative fatigue in future studies.

Several limitations of this present study must be considered. Firstly, our study is a cross-sectional design, and the causal relationship between variables is not yet conclusive, and further prospective studies are needed to identify the influencing factors and changes in the quality of life of PA patients. Secondly, this study was only followed up for one year, the long-term fatigue level of PA patients and related influencing factors remain to be further explored. The future studies should be focused on the related interventional research to improve the fatigue based on the factors that influence the fatigue of PA patients.

In conclusion, the level of fatigue in PA patients after surgery is negatively correlated with the time course after surgery and physical activity. Future studies should put more attention to the fatigue, sleep and activity of PA patients after surgery. Exercise and sleep intervention strategies may be potentially effective to reduce the fatigue, thereby improving the quality of life of PA patients after surgery.

\section{Acknowledgments}

Funding: This research received grant from the Postgraduate Research \& Practice Innovation Program of Jiangsu Province (KYCX17_2029).

\section{Footnote}

Conflicts of Interest: All authors have completed the ICMJE uniform disclosure form (available at http://dx.doi. 
org/10.21037/tcr.2020.02.47). The authors have no conflicts of interest to declare.

Ethical Statement: The authors are accountable for all aspects of the work in ensuring that questions related to the accuracy or integrity of any part of the work are appropriately investigated and resolved. The study was conducted in accordance with the Declaration of Helsinki (as revised in 2013). This study was approved by the Medical Research Ethics Committee of First Affiliated Hospital of Soochow University (No.20170167) and informed consent was taken from all individual participants.

Open Access Statement: This is an Open Access article distributed in accordance with the Creative Commons Attribution-NonCommercial-NoDerivs 4.0 International License (CC BY-NC-ND 4.0), which permits the noncommercial replication and distribution of the article with the strict proviso that no changes or edits are made and the original work is properly cited (including links to both the formal publication through the relevant DOI and the license). See: https://creativecommons.org/licenses/by-nc-nd/4.0/.

\section{References}

1. Molitch ME. Diagnosis and Treatment of Pituitary Adenomas: A Review. JAMA 2017;317:516-24.

2. Sinclair G, Olsson M, Benmakhlouf H, et al. Pituitary carcinomas: Rare and challenging. Surg Neurol Int 2019;10:161.

3. Mete O, Lopes MB. Overview of the 2017 WHO Classification of Pituitary Tumors. Endocr Pathol 2017;28:228-43.

4. Iglesias P, Rodriguez Berrocal V, Diez JJ. Giant pituitary adenoma: histological types, clinical features and therapeutic approaches. Endocrine 2018;61:407-21.

5. Pal A, Leaver L, Wass J. Pituitary adenomas. BMJ 2019;365:12091.

6. Waddle MR, Oudenhoven MD, Farin CV, et al. Impacts of Surgery on Symptom Burden and Quality of Life in Pituitary Tumor Patients in the Subacute Post-operative Period. Front Oncol 2019;9:299.

7. van der Klaauw AA, Kars M, Biermasz NR, et al. Diseasespecific impairments in quality of life during long-term follow-up of patients with different pituitary adenomas. Clin Endocrinol (Oxf) 2008;69:775-84.

8. Hauser BM, Lau A, Gupta S, et al. The Epigenomics of Pituitary Adenoma. Front Endocrinol (Lausanne)
2019;10:290.

9. Webb SM, Crespo I, Santos A, et al. MANAGEMENT OF ENDOCRINE DISEASE: Quality of life tools for the management of pituitary disease. Eur J Endocrinol 2017;177:R13-R26.

10. Snyder R, Fayed I, Dowlati E, et al. Pituitary Adenoma and Craniopharyngioma Collision Tumor: Diagnostic, Treatment Considerations, and Review of the Literature. World Neurosurg 2019;121:211-6.

11. Mustian KM, Alfano CM, Heckler C, et al. Comparison of Pharmaceutical, Psychological, and Exercise Treatments for Cancer-Related Fatigue: A Meta-analysis. JAMA Oncol 2017;3:961-8.

12. Boguszewski CL, de Castro Musolino NR, Kasuki L. Management of pituitary incidentaloma. Best Pract Res Clin Endocrinol Metab 2019;33:101268.

13. Laws ER Jr, Penn DL, Repetti CS. Advances and controversies in the classification and grading of pituitary tumors. J Endocrinol Invest 2019;42:129-35.

14. Yi LS, Alias A, Ghani ARI, et al. Endocrinological Outcome of Endoscopic Transsphenoidal Surgery for Functioning and Non-Functioning Pituitary Adenoma. Malays J Med Sci 2019;26:64-71.

15. Fernandes-Junior SA, Ruiz FS, Antonietti LS, et al. Sleep, Fatigue and Quality of Life: A Comparative Analysis among Night Shift Workers with and without Children. PLoS One 2016;11:e0158580.

16. Biermasz NR. The burden of disease for pituitary patients. Best Pract Res Clin Endocrinol Metab 2019;33:101309.

17. Chu X, Zhang Y, Tuo L, et al. Spontaneous cerebrospinal fluid rhinorrhea associated with an incidental pituitary adenoma. Br J Neurosurg 2019:1-4.

18. Brandenbarg D, Korsten JHWM, Berger MY, et al. The effect of physical activity on fatigue among survivors of colorectal cancer: a systematic review and meta-analysis. Support Care Cancer 2018;26:393-403.

19. Bahmer T, Watz H, Develaska M, et al. Physical Activity and Fatigue in Patients with Sarcoidosis. Respiration 2018;95:18-26.

20. Ho KKY, Fleseriu M, Wass J, et al. A tale of pituitary adenomas: to NET or not to NET : Pituitary Society position statement. Pituitary 2019;22:569-53.

21. Buchfelder M, Schlaffer SM, Zhao Y. The optimal surgical techniques for pituitary tumors. Best Pract Res Clin Endocrinol Metab 2019;33:101299.

22. Prabhu S, Prabhu S. Pituitary Prolactinoma with Amyloid Deposits: Surgery or Dopamine Agonists? Review of Previous Reports and New Recommendations for 
Management. Asian J Neurosurg 2019;14:754-8.

23. Wu Y, Gao L, Guo X, et al. Pituitary adenomas in patients with multiple endocrine neoplasia type 1: a single-center experience in China. Pituitary 2019;22:113-23.

24. Sommerfelt H, Sagberg LM, Solheim O. Impact of transsphenoidal surgery for pituitary adenomas on overall health-related quality of life: a longitudinal cohort study. Br J Neurosurg 2019;33:635-40.

25. Crouzeix G, Morello R, Thariat J, et al. Quality of Life but not Cognition is Impacted by Radiotherapy in Patients with Non-Functioning Pituitary Adenoma. Horm Metab Res 2019;51:178-85.

26. Vega-Beyhart A, Enriquez-Estrada VM, Bello-Chavolla $\mathrm{OY}$, et al. Quality of life is significantly impaired in both secretory and non-functioning pituitary adenomas. Clin Endocrinol (Oxf) 2019;90:457-67.

27. Hayhurst C, Taylor PN, Lansdown AJ, et al. Current perspectives on recurrent pituitary adenoma: The role and timing of surgery vs adjuvant treatment. Clin Endocrinol (Oxf) 2020;92:89-97.

28. Zhang Y, Pan Q, Jiang H, et al. A prospective study of headache and neuropeptides in patients with pituitary adenomas. Cephalalgia 2019;39:1049-57.

29. Joustra SD, Thijs RD, van den Berg R, et al. Alterations in diurnal rhythmicity in patients treated for nonfunctioning pituitary macroadenoma: a controlled study and literature review. Eur J Endocrinol 2014;171:217-28.

30. Borodkin K, Ayalon L, Kanety H, et al. Dysregulation of circadian rhythms following prolactin-secreting pituitary microadenoma. Chronobiol Int 2005;22:145-56.

31. Villa C, Vasiljevic A, Jaffrain-Rea ML, et al. A standardised diagnostic approach to pituitary neuroendocrine tumours (PitNETs): a European Pituitary Pathology Group (EPPG) proposal. Virchows Arch 2019;475:687-92.

32. Wood LJ, Nail LM, Winters KA. Does muscle-derived interleukin-6 mediate some of the beneficial effects of exercise on cancer treatment-related fatigue? Oncol Nurs Forum 2009;36:519-24.

33. Serdà I Ferrer BC, van Roekel E, Lynch BM. The Role of Physical Activity in Managing Fatigue in Cancer Survivors. Curr Nutr Rep 2018;7:59-69.

34. García-Álvarez M, Climent V. Sleep apnea and cardiovascular complications of the acromegaly. Response to the medical treatment. Minerva Endocrinol 2019;44:159-68.

35. Asha MJ, Takami H, Velasquez C, et al. Long-term outcomes of transsphenoidal surgery for management of growth hormone-secreting adenomas: single-center results. J Neurosurg 2019:1-11.

36. Abrahams HJG, Gielissen MFM, Braamse AMJ, et al. Graded activity is an important component in cognitive behavioral therapy to reduce severe fatigue: results of a pragmatic crossover trial in cancer survivors. Acta Oncol 2019;58:1692-8.

37. Larun L, Brurberg KG, Odgaard-Jensen J, et al. Exercise therapy for chronic fatigue syndrome. Cochrane Database Syst Rev 2017;4:CD003200.

38. Dennett AM, Peiris CL, Shields N, et al. Moderateintensity exercise reduces fatigue and improves mobility in cancer survivors: a systematic review and meta-regression. J Physiother 2016;62:68-82.
Cite this article as: Zhao X, Wang T, Sheng G, Tang Y, Shen M, Yang J. The fatigue, sleep and physical activity in postoperative patients with pituitary adenoma: what we can do. Transl Cancer Res 2020;9(3):1779-1786. doi: 10.21037/ tcr.2020.02.47 